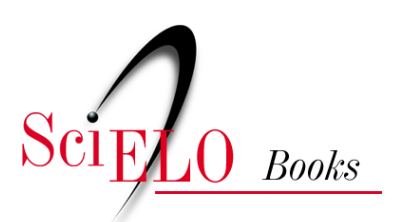

\title{
Apresentação e agradecimentos
}

\author{
Edward MacRae
}

\section{SciELO Books / SciELO Livros / SciELO Libros}

MACRAE, E., Apresentação e agradecimentos. In: A construção da igualdade-política e identidade homossexual no Brasil da "abertura" [online]. Salvador: EDUFBA, 2018, pp. 15-18. ISBN 978-85-2321998-7. https://doi.org/10.7476/9788523219987.0002.

All the contents of this work, except where otherwise noted, is licensed under a Creative Commons Attribution 4.0 International license.

Todo o conteúdo deste trabalho, exceto quando houver ressalva, é publicado sob a licença Creative Commons Atribição 4.0. 


\section{Apresentação e agradecimentos}

Este livro é o resultado da pesquisa bibliográfica e de campo, que realizei entre 1978 e 1985, para minha tese de doutorado em antropologia: O militante homossexual no Brasil da "abertura", apresentada em janeiro de 1986 ao Departamento de Ciências Sociais da Faculdade de Filosofia, Letras e Ciências Humanas da Universidade de São Paulo. Foi reescrita para publicação em 1988 e finalmente teve sua primeira edição, pela Editora da Unicamp, em 1990.

Durante esses anos, e, também, enquanto reordenava o material para publicação, contei com a orientação, apoio e amizade de um número muito grande de pessoas, cuja contribuição foi crucial.

É impossível agradecer nominalmente a todos os meus interlocutores, integrantes dos grupos e partidos Somos-SP, GALF, Outra Coisa, Eros, Libertos, Lampião, Somos-RJ, Auê, Grupo Gay da Bahia, Adé Dudu, GATHO, Beijo Livre, Dialogay, Bando de Cá, Coletivo Alegria Alegria, Moléculas Malucas, Terra Maria, Triângulo Rosa, Nós Mulheres, Brasil Mulher, SOS Mulher, Movimento Negro Unificado, PT, PMDB, Convergência Socialista, ao lado de quem tive a oportunidade de discutir a militância política sexual.

O contato com todos esses pontos de vista diferentes e conflitivos, naturalmente resultou num emaranhado de ideias difícil de organizar. A ordem que aparece aqui só pôde surgir graças à cuidadosa orientação 
de meus mestres, Peter Fry e Eunice R. Durham, a quem, além da orientação teórica, devo também muitos dos insights deste trabalho.

Não posso esquecer outros que também me ajudaram a pensar mais teoricamente sobre o assunto lendo trechos de minha tese, dando sugestões ou permitindo-me usar seu próprio material de pesquisa. Agradeço aos professores Luis Mott, Mariza Correa, Verena Stolke, Ruth Cardoso, Oraci Nogueira, Lux Vidal, J. A. Guilhon de Albuquerque, Maria Moraes, Ulisses Ferraz de Oliveira, Júlio Simões, Jorge Beloqui, Pedro Sousa, Matheus Rogatto, Heloísa Pontes, Maria Filomena Gregori, Nestor Perlongher, Vic Seidler, Ernani Pinheiro Chaves, Cláudio P. Coelho, Carmen D. Guimarães, Eduardo Guimarães, Wilson Santos, Richard Parker, Osvaldo Fernandez, Jean Claude Bernardet, Leila Micolis, João Antônio Mascarenhas, Paulo Ottoni, Ricardo C. Pereira, Roseli Roth, Antônio Carlos Tosta, Theodoro Pluciennik, Paulo César Bonfim, Darcy Penteado, João Silvério Trevisan, Glauco Mattoso, Jimmy Green e Severino do Ramo.

Num nível mais informal, mas igualmente importante, devo muito aos meus papos com tantos bons amigos, que têm convivido comigo nestes últimos anos: Ulisses, Ricardo A., Eduardo T., Edson, Marquinhos, Luiz A., Milton, Marcelo, Vilma, Pitú, Teca, Paulo Afonso, Jacira, Mariza, Silas, Zezé, Shuma, Evaristo, Míriam, Hélinho, João Luiz, Luzenário, Ricardo V., Sisi, Israel, Cláudio Motoqueiro, Alexandre, Aroldo, Marivaldo, Wilson D., Amauri, Jerson, Rocha, Juba, Denise, Dilza, Cristiano e Cláudia Wonder.

Um grupo de amigos muito especial foi aquele com quem compartilhei morada nestes últimos anos. Além de dar novas ideias, foram especialmente tolerantes em momentos em que nossa residência foi usada para movimentadas reuniões políticas: Neide Duarte, Anita Jorge, Jussara Amoroso Dias, Júlio Dias Gaspar, Silvana Issa Afram, Fernando de Almeida, Marcos Rogatto e Beto Ronchezel. Nos traumáticos momentos de elaboração de relatório de pesquisa, contei com a companhia de Júlio Assis Simões, para "retiros acadêmicos", altamente produtivos, em Campos de Jordão e Caraguatatuba. Seu conhecimento antropológico e sua biblioteca de ciências sociais, às vezes, me pareciam inesgotáveis.

Durante um período crucial do meu trabalho de campo, fui acometido de hepatite quando pude contar com devotados enfermeiros: meus irmãos Alan e Marina e o amigo Laerth Pedrosa. 
Minhas pesquisas levaram-me também a realizar agradabilíssimas viagens a Salvador, onde o Grupo Gay da Bahia e Luiz Mott puseram à minha disposição os seus riquíssimos arquivos. Também desenvolvi duradouras amizades com Harley Henriques do GAPA-BA, Jerson Matos, Antonio Rocha e Amauri. Nessas, como em outras ocasiões, contei com a maravilhosa hospitalidade de Sofia Olszewski, que me ensinou a ver e amar aquela terra.

Reescrevi a tese para publicação enquanto trabalhava como pesquisador do Conselho Nacional de Desenvolvimento Científico e Tecnológico (CNPq) sediado no Instituto de Medicina Social e de Criminologia de São Paulo (IMESC). Lá fui muito ajudado pelo superintendente Carlos Vicari Jr., além de Maria Etelvina Reis de Toledo Barros, a querida Telva, que tem sido uma amiga de toda hora, dentro e fora do IMESC.

Para o complicado trabalho de datilografia do meu manuscrito, contei com a paciência e o bom humor de Naira N. Ciotti e Milton Filippetti Filho e da militante lésbica feminista Alice, laboriosos críticos e revisores.

A pesquisa começada na Unicamp e terminada na Universidade de São Paulo (USP) foi financiada com bolsas da Coordenação de Aperfeiçoamento de Pessoal de Nível Superior (CAPES) e da Fundação de Amparo à Pesquisa do Estado de São Paulo (FAPESP). A tese original foi transformada em livro enquanto eu era bolsista recém-doutor do Conselho Nacional de Desenvolvimento Científico e Tecnológico (CNPq).

Passados vinte e sete anos da edição original do livro, alguns orientandos e outros amigos instaram-me a republicar o material. Argumenta-se que a edição original teve uma pequena tiragem, que há muito se esgotou, e que o texto, o primeiro estudo acadêmico do movimento homossexual no Brasil, continua a ser de interesse de pesquisadores do tema, agora acrescido de significado como registro histórico de um determinado momento. Revendo o material que produzi naqueles anos, decidi adicionar mais três artigos que versavam sobre questões identitárias e políticas enfrentadas pelos homossexuais, militantes ou não, na virada das décadas de 1970 e 1980, durante o período em que se convencionou chamar de "abertura democrática", quando a ditadura civil-militar começava a dar sinais de fadiga. Também achei importante submeter meu texto original a uma rigorosa e necessária copidescagem, usufruindo do maior desembaraço com a língua 
portuguesa, adquirido durante anos de trabalho na Universidade Federal da Bahia, onde me ingressei como professor em 1995.

Neste novo momento, volto a contar com o auxílio de outros amigos que muito me têm ajudado, nesta e em outras tarefas de cunho profissional e pessoal. Lembro aqui de meu assistente de pesquisa e grande amigo Wagner Coutinho Alves, o Joey, que passou muitas horas com a reorganização do material, de Flávia Goulart Mota Garcia Rosa, diretora da Editora da Universidade Federal da Bahia e de Susane Barros, da sua coordenação editorial. Também tenho recebido importante apoio afetivo do meu companheiro Sandro Pimentel, idealizador do projeto original da capa deste livro. Não posso deixar de mencionar também os velhos amigos Ulisses Ferraz de Oliveira e Mauro Monti, assim como meu sobrinho João Leal MacRae e Isaias Santos, que sempre me brindam com suas agradabilíssimas companhias durante minhas idas a São Paulo. Importantes também foram os incentivos de meus amigos James Green, Leandro Colling, Tedson Sousa e Vinícius Alves que, em diferentes momentos, apontaram a continuada relevância, para os tempos atuais, destes textos sobre a identidade, o movimento e a "movimentação" homossexuais.

Meu pai, Alan MacRae, esteve presente na defesa de minha tese e generosamente me premiou com uma longa viagem. Sua orgulhosa reação ao meu sucesso acadêmico foi muito importante para mim. Fizemos a viagem algum tempo depois, na companhia de minha mãe, mas poucos dias após sua volta, quando eu ainda estava fora, veio a falecer repentinamente. Durante aquela viagem tivemos a possibilidade de estabelecer uma definitiva reconciliação, encerrando um período de rusgas, típicas da minha fase de vida de adolescente e de jovem ainda em amadurecimento. Quatro anos depois, meu queridíssimo irmão Alan também partiu, vítima da aids, três dias após minha família ter todas as suas reservas financeiras congeladas pelo sinistro Plano Collor. Minha mãe, Dulce Baptista das Neves Gonçalves MacRae (Dolly), foi meu esteio emocional durante vários anos difíceis que se seguiram. Sua força, inteligência e carinho pareciam inesgotáveis. Afortunadamente, pude contar com sua companhia por mais um bom tempo. Ao partir, por sua vez, em 2011, deixou maravilhosas lembranças para todos que a conheceram e especialmente para mim, meus irmãos, Marina e Alexander, sua nora Claudia, e seu neto, João. 